\title{
Seed Viability Changes during Fruit Ripening of Juniperus polycarpos: Implications for Seed Collection
}

\author{
Mojtaba Mohammadi Zade (1), Hadi Kiadaliri ${ }^{(1) \#,}$ Vahid Etemad $^{(2)}$, Iraj Mehregan ${ }^{(1)}$, \\ Reza Azizinezhad ${ }^{(1)}$ \\ Faculty of Natural Resources, Science and Research Branch, Islamic Azad University, \\ Tehran, Iran; "Department of Forestry and Forest Economics, Faculty of Natural \\ Resources, University of Tehran, Chamran Blvd. Karaj, Alborz, Iran.
}

\begin{abstract}
TNIPERUS polycarpos is a keystone species found in arid zones in the Middle East, especially in Iran. Although studies have researched how to increase the germination capacity of this species through seed treatments, other methods to increase seed germination capacity have not been investigated. In this study, we considered the effects that seed collection time had on the germination parameters of J. polycarpos. The germination parameters were calculated for each treatment, which was replicated 4 times with 100 seeds per replicate. The results showed that all germination parameters were affected by a high degree of infestation, which increased significantly from $10 \%$ in August (unripe cones) to $39 \%$ in November (ripe cones). Seed infestation caused the seed viability, germination capacity, and germination value of the seeds to decrease by $67 \%, 78 \%$, and $95 \%$, respectively. The decrease in germination capacity could have also resulted from the probable high amount of abscisic acid in mature cones. Therefore, collecting cones four months earlier than the maturation time may be a more cost effective method for the artificial regeneration of forests and the seedling production of $J$. polycarpos. Early collection time combined with the best introduced treatment methods can significantly improve the germination of $J$. polycarpos seeds. This will be useful for artificial regeneration practices in endangered and genetically unique stands of $J$. polycarpos.
\end{abstract}

Keywords: Forestry, Restoration, Germination, Seed collection, Seed infestation.

\section{Introduction}

Juniper forests are one of the most widespread forests in the world. They stretch from the Piñon-juniper woodlands of Western United States, which is a 22 million ha in size (Mitchell \& Roberts Jr, 1999), to Central and East Asia (Adams, 2014). Most juniper forests are comprised of dioecious species, including Juniperus polycarpos K. Koch (Korouri et al., 2012). Juniper forests are one of the most valuable forests found in arid zones and harsh climates which can both conserve soil from erosion and keep wildlife diversity at optimum. Over the past few decades, Iran's juniper forests have been degraded as a result of human activities from 1.2 million ha in 1970 to 500 thousand ha in early 2000 (Kharazipour, 2009). Therefore, most of Iran's juniper forests are highly fragmented, which threatens the natural reproduction of these forests; a recent study observed no signs of natural regeneration in healthy forests of Khorasan province (Ahani et al., 2013). Fragmentation reduces the seed banks of forests (Martins \& Engel, 2007), especially coniferous forests found in arid zones, juniper forests (Santos \& Tellería, 1994 and Korouri et al., 2012).

A key stage in the life cycle of plants is the seed stage. This is the stage at which the plant is most vulnerable to environmental factors, particularly pests (Baskin, 2017). However, most plants adopt strategies to reduce the exogenous effects on this very fragile part of their life cycle. Seed dormancy is one of the main strategies that plants use to escape unfavorable environmental conditions, including competition and herbivory, although it has a detrimental effect on the germination process (Penfield, 2017).

Many studies have proved that germination 
parameters are affected by several factors, such as the genetic structure of a single plant in a population (Yuan et al., 2016). Although there are many aspects of germination are yet to be discovered, studies have determined that seed dormancy is a main influential factor (Baskin \& Baskin, 2014). Studies on quantitative genetics and mutant approaches have identified that seed germination is controlled by the interactions between a large number of genes and developmental and environmental factors (Kerdaffrec \& Nordborg, 2017). Many studies have also focused on breaking seed dormancy (Koornneef et al., 2002; Mamo et al., 2006; Pinna et al., 2014 and Daneshvar et al., 2016). It should be noted that while seed collection occurs prior to seed treatment, this step in the practice of artificial forest regeneration is sometimes neglected, especially for conservation of the trees. Recent publications on seed collection have focused on the criteria used for population and tree selection (Guerrant Jr et al., 2015). Most studies have identified the end of seed development as the proper time for seed collection (Baskin \& Baskin, 2014).

Another intervening factor on seed germination is seed infestation by pests and diseases which lead us to the use of some treatments (Gowthami et al., 2016), however, in forests, the seeds will be infested even before they leave the mother tree, especially during this changing climate (Ramsfield et al., 2016). In nature, seed germination in trees with nutritional seeds like species of Acacia genus can be affected considerable by pests (Andersen et al., 2016 and Rugemalila et al., 2017). Rugemalila et al. (2017) found that $33 \%$ of $A$. tortilis and $61 \%$ of $A$. robusta seeds was infested in 2014, which can severely affect natural regeneration of these species. In this regard, Daneshvar et al. (2017) found that 75 to $82 \%$ of $J$. polycarpos seeds was empty and insect-infested, but they didn't go deep in the case.

Since the time of seed collection is very important to forest restoration practices, forest practitioners should be familiar with mast years and the best collection time for keystone species. This species has a very low GC; Daneshvar et al. (2016) found that about $70 \%$ of treated viable seeds germinated compared with less than $10 \%$ of viable seeds that were not treated. Thus, all possible treatments should be studied to determine which treatment produces the best germination results.

Hence, the aims of this study were to specify the best seed collection time during fruit development and to assess the effect of seed collection time on seed infestation and germination parameters, including germination capacity (GC), germination speed (GS), mean germination time (MGT), germination value $(\mathrm{GV})$, and seed viability $(\mathrm{SV})$.

\section{Materials and Methods}

\section{Site description}

The cones were gathered from a pure $J$. polycarpos stand located in Kerman Province, south of Iran. In 1995, the 382 ha stand area was registered as a protected area and gene bank of $J$. polycarpos. Sampling was done during 2011, which was a mast year, on day 23 of four consecutive months: August, September, October, and November. The sampling area was located between $29^{\circ} 17^{\prime} 24^{\prime \prime}-29^{\circ} 18^{\prime} 42^{\prime \prime} \mathrm{N}$ and $57^{\circ} 04^{\prime} 32^{\prime \prime}$ $57^{\circ} 06^{\prime} 48^{\prime \prime} \mathrm{E}$ at 1350 to $2850 \mathrm{~m}$ above sea level (Fig. 1). According to (Peel et al., 2007), the forest is classified as hot arid steppes (BSh) with an annual precipitation of $200 \mathrm{~mm}$ and average temperature of $25.1^{\circ} \mathrm{C}$.

\section{Samplin of seeds}

To take a representative sample of the stand, 30 random plots were defined in the area and the nearest seed tree in each plot was identified as the sampling tree. The diameter at breast height of the sampling trees was between $40 \mathrm{~cm}$ and $55 \mathrm{~cm}$. All the samples were taken from the same tree. As the seed samples should be representative, cones were collected from the accessible parts of the tree crown (Daneshvar et al., 2016). After the seeds were collected each month, they were packed in plastic bags and stored in a refrigerator at $5^{\circ} \mathrm{C}$ until the final collection was completed. Because the cones collected early were very hard, physical methods were used to break the cones and extract the seeds. All seeds, including viable, empty, wooden, dead, and infested seeds, were counted using a scalpel for each treatment, which was replicated 4 times with 100 seeds per replicate.

\section{Treatment protocol and germination test}

A 10 -week period of cold stratification was used to break seed dormancy. Four replicates of 100 seeds for each collection time were treated with cold stratification. Seed resin was washed 
using acetone according to the procedure described by Daneshvar et al. (2016). Seeds were soaked in water for $48 \mathrm{~h}$ before stratification to absorb adequate moisture. Cold stratification was done at $4^{\circ} \mathrm{C}$ in polyethylene dishes using a combination of sterilized sand and seeds at a ratio of $4: 1$ to reduce the fluctuation in moisture. Moisture content was kept at $30 \%$ using the procedure developed by Daneshvar et al. (2016). As the dishes were not sealed to permit aeration, they were weighed once every 4 days to control moisture content.

After 10 weeks of cold stratification, the seeds were separated from the sand. The germination experiment was conducted on the 4 replicates of 100 seeds for each treatment (collection time) simultaneously. The germination experiment was done in the nursery field to represent the natural conditions of seed germination. A 5-cm layer of sterilized sand covered the standard nursery soil to prevent seed infection. Seeds were sown on the sand medium and covered with a 1-cm layer of sand. The area was irrigated regularly using a spray irrigation method for 70 days, which was longer than the recommended time by the International Seed Testing Association (ISTA). Germinated seeds were counted regularly during the period according to ISTA rules.

\section{Data analysis}

The germination parameters for all replications were calculated using the following equations:

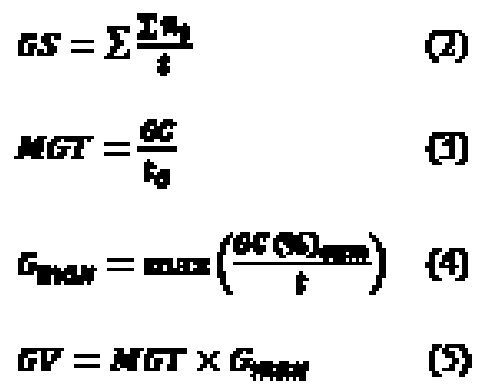

where $\Sigma n_{i}$ is the number of germinated seeds after 70 days, $N$ is the total number of sown seeds for each replication (100), $\Sigma n_{t}$ is the number of germinated seeds until day $t, t$ is the day the germinated seeds were counted, $t_{G}$ is the number of days from sowing until the last germination (70 days), $\mathrm{GC}(\%)_{\text {cum }}$ is the cumulative germination during the period $t$, and $G_{\max }$ is the maximum germination during the germination time. SV was determined by cutting another 100 seeds using scalpel.
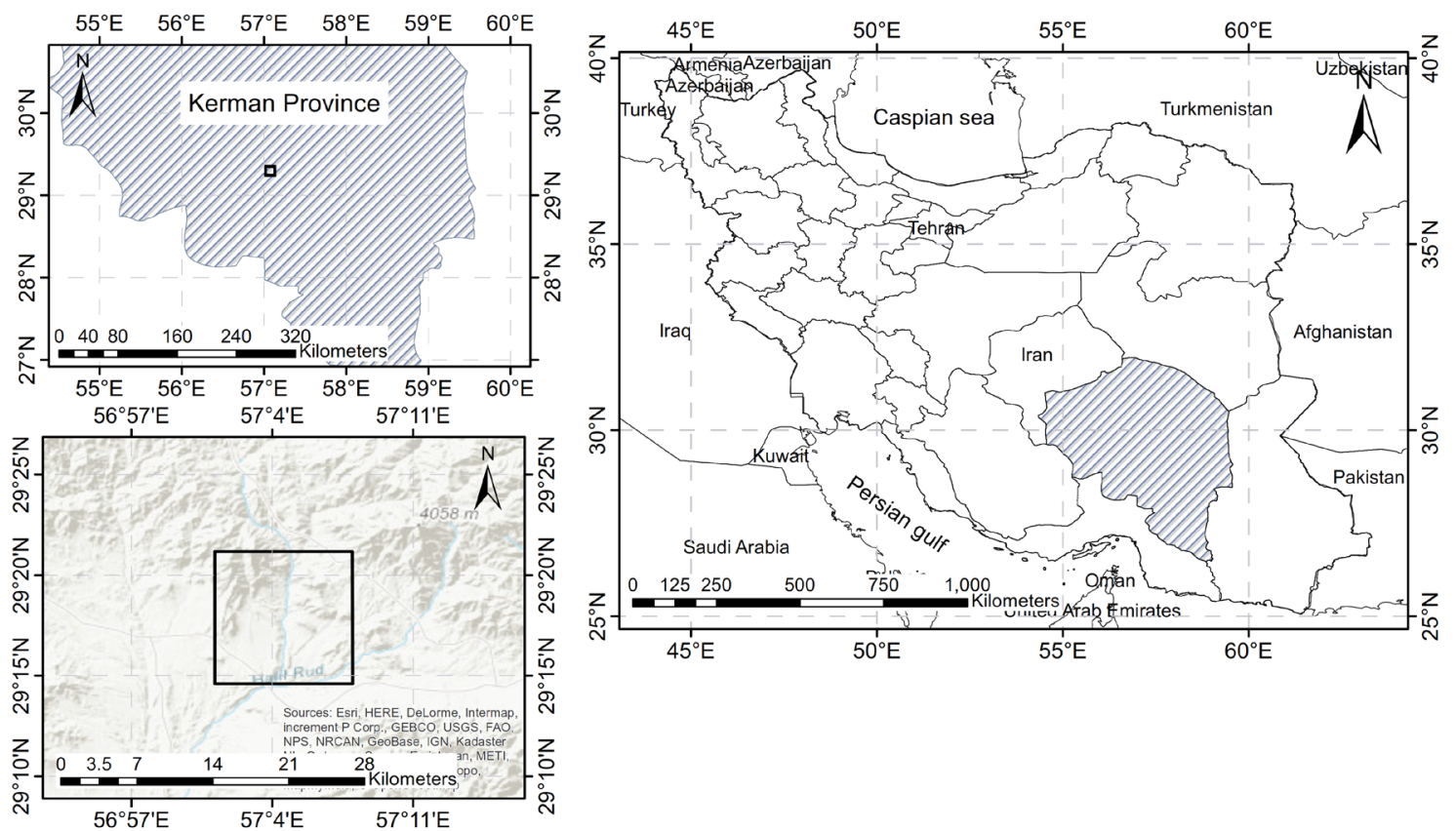

Fig.1. Location map of the study area in Kerman province, Iran. 
All parameters were analyzed using the one-way analysis of variance (ANOVA) with collection time as the independent variable. No transformations were done on the data because no violations of the assumptions were detected (Gomez \& Gomez, 1984). Mean comparisons were conducted on the variables that showed significant ANOVA results. The means of the four treatments were compared using the Duncan's multiple range test at 5\% significant levels. All statistical procedures were done using SAS $^{\circledR} 9.4$ statistical software (SAS Institute, NC, United States).

\section{Results}

Statistical analysis showed that the collection time had a very significant effect on the germination parameters and seed properties of $J$. polycarpos. Table 1 shows that all germination parameters changed during fruit ripening, although the seed properties were less affected. The number of vacant seeds was not affected over time; however, the number of infested seeds changed considerably. The effect of time on the number of wooden seeds was not as significant as the other parameters.

The Duncan comparison of means showed that all germination parameters decreased over time (Fig. 2). The GC decreased significantly over the four-month period from $23 \%$ to $5 \%$, which equates to an approximate $5 \%$ reduction in GC per month. SV decreased from $52 \%$ in unripe cones to $20 \%$ in ripe cones. This indicates that the seeds of unripe cones have a high GC. One of the most affected parameters was $\mathrm{GV}$, which decreased drastically from 0.164 in unripe cones to 0.008 in ripe cones, which was 20 times lower than in unripe cones. The MGT decreased significantly from 0.32 to 0.07 . In other words, we expect five seeds to germinate in unripe cones, while we expect one seed to germinate in ripe cones over 14 days.

Among seed properties, wooden seeds were more common in unripe cones than in ripe cones, although the difference was about $2 \%$, which was negligible. However, the number of infested seeds increased during fruit ripening. The lowest number of infested seeds was observed in August when only $10 \%$ of the seeds were infested. In ripe cones, the number of infested seeds increased to $39 \%$, which is a considerable increase over 4 months.

\section{Discussion}

The GC of juniper seeds is very low and, thus, many studies have been conducted to find the best treatments to increase the GC (Tilki, 2007; Barbour \& Carvalho, 2009; El-Juhany et al., 2009; Tylkowski, 2009; Tauer et al., 2011; Daneshvar, 2015; Daneshvar et al., 2015 and Daneshvar et al., 2016), however, the effect of other factors on germination parameters are yet unknown. In this paper, we showed that the SV of $J$. polycarpos is extremely affected by infestation during fruit ripening over a 4-month period. All germination parameters decreased significantly during this period, which indicates that natural stand regeneration is a great challenge. Because unripe cones are so hard, they do not permit infestation and insect penetration, although ripe cones are easy to penetrate. Our research showed that collecting cones 3 months earlier than the phenological time increased the GC of seeds significantly: from $25 \%$ in November to $44 \%$ in August in viable seeds. The decrease in germination parameters of viable seeds from August to November is thought to be the result of abscisic acid production during late embryogenesis, which resulted in chemical dormancy of the seeds (Batygina, 2009). Therefore, collecting cones in August results in a lower level of chemical dormancy.

TABLE 1. Analysis of variance of the germination parameters and seed properties of $J$. polycarpos

\begin{tabular}{|c|c|c|c|c|c|c|c|c|c|}
\hline & GC & GS & $\mathbf{G}_{\max }$ & MGT & GV & SV & Wooden & Vacant & Infested \\
\hline $\begin{array}{l}\text { Mean } \\
\text { square }\end{array}$ & 258.7 & 0.123 & 0.525 & 0.0513 & 0.06 & 755 & 3.23 & 20.7 & 633 \\
\hline Error & 0.5 & $2.5 \times 10^{-4}$ & $2.2 \times 10^{-4}$ & $9.9 \times 10^{-5}$ & $2.9 \times 10^{-5}$ & 3 & 0.73 & 9 & 3.25 \\
\hline F & 517 & 499 & 231 & 517 & 678 & 252 & 4.43 & 2.3 & 195 \\
\hline $\operatorname{Pr}>\mathrm{F}$ & $\begin{array}{c}< \\
0.0001\end{array}$ & $\begin{array}{c}< \\
0.0001\end{array}$ & $\begin{array}{c}< \\
0.0001\end{array}$ & $\begin{array}{c}< \\
0.0001\end{array}$ & $\begin{array}{c}< \\
0.0001\end{array}$ & $\begin{array}{c}< \\
0.0001\end{array}$ & 0.05 & ns & $\begin{array}{c}< \\
0.0001\end{array}$ \\
\hline
\end{tabular}



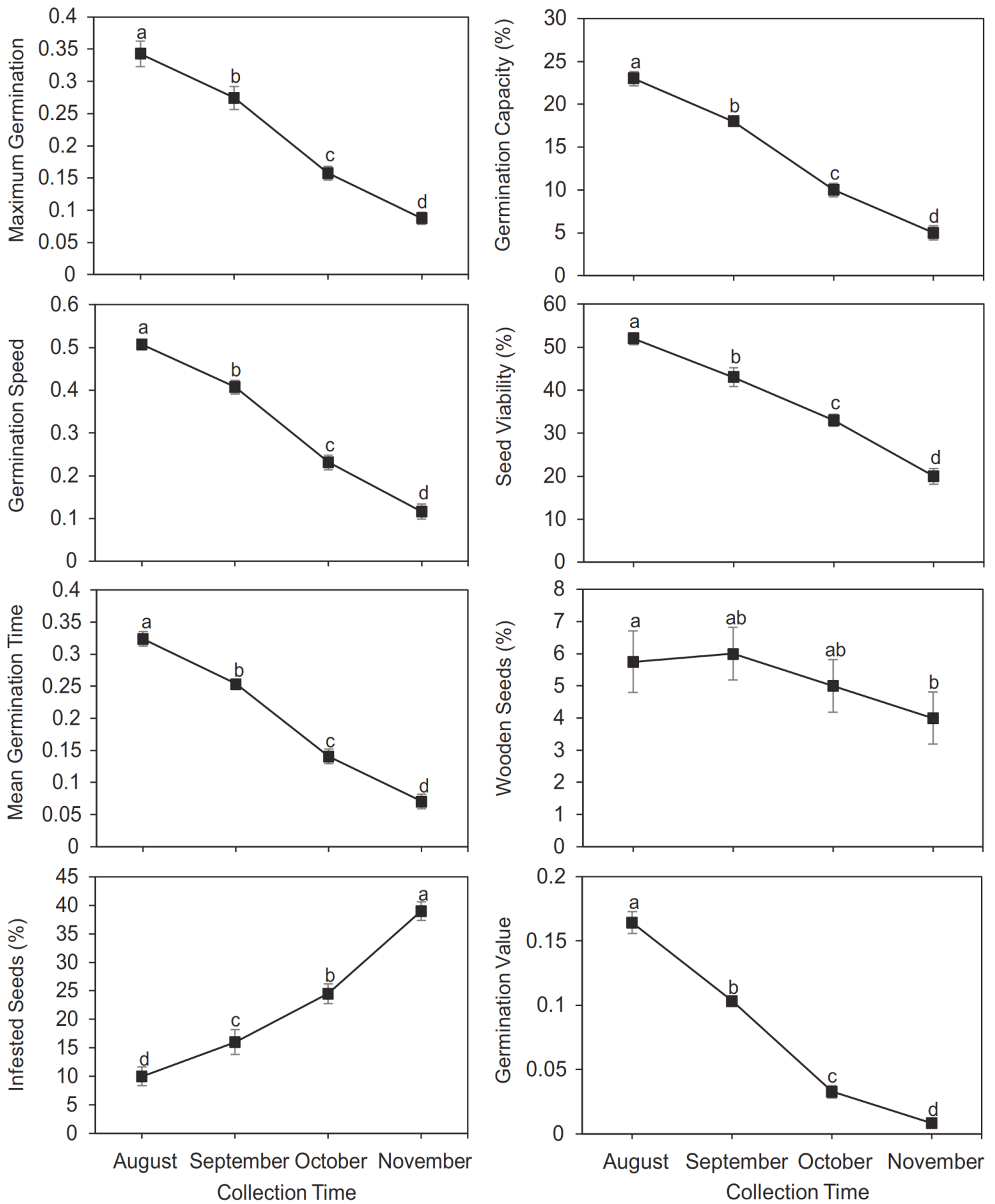

Fig. 2. Germination parameters and seed properties during fruit ripening of J. polycarpos; the error bars represent the standard deviation of the treatments. The letters indicate significant differences at 0.01 alpha level (the percentage of wooden seeds were compared at $\alpha=0.05$ ) for Duncan's multiple range test.

During the fruit ripening period, SV decreased from $52 \%$ to $20 \%$, which is a $67 \%$ reduction in GC due to infestation. GC decreased from $23 \%$ to $5 \%$, which shows a $78 \%$ reduction. This indicates that the GC was affected not only by a decrease in viable seeds as a result of infestation, but also seed aging in the cones (Darrudi et al., 2015) or by the high levels of $\mathrm{ABA}$ in the seeds of ripe cones (Batygina, 2009). The GC of viable seeds that were collected in November agree with the 
results obtained by the 10 -week cold stratification treatment by Daneshvar et al. (2016), which was $25 \%$, although the stratification temperature in this study was $3^{\circ} \mathrm{C}$ higher than the temperature used by Daneshvar et al. The seeds collected in August showed a 44\% GC in viable seeds.

Few studies have been conducted on the GC changes that occur during cone maturation of coniferous species. Tillman-Sutela \& Kauppi (2014) showed that the GC of Pinus sylvestris can change significantly during cone maturation. They found that in warm forests, GC decreased significantly during the first year of cone maturation, although it increased the following year. However, in cold forests, the GC increased with cone maturation. These contradictory results should be studied more accurately to determine the causes of the differences.

One of the most important germination parameters in forest restoration practices is the GV (Czabator, 1962). In this study, the GV indicated the most cost effective time for cone collection. We found that the $\mathrm{GV}$ of the juniper seeds decreased from 0.16 in August to 0.008 in November, which was a significant $95 \%$ reduction in GV. Therefore, the early collection of juniper cones is more cost effective than the collection of mature and ripe cones for forest restoration practices.

\section{Conclusion}

In this experiment, we considered changes in germination parameters and seed properties during cone maturation of $J$. polycarpos. Early collection of cones will have better results for forestry practices because of the lower seed infestation and lower chemical dormancy. These variables accounted for a $78 \%$ increase in seed $\mathrm{GC}$, a $67 \%$ increase in $\mathrm{SV}$, and a $95 \%$ increase in $\mathrm{GV}$ of the juniper seeds. Although the stratification treatment that was used in this study was not the best method according to Daneshvar et al. (2016), combining an early collection time with the best introduced treatment methods can significantly improve the germination of $J$. polycarpos seeds. This will be useful for artificial regeneration and reforestation practices in endangered and unique stands of $J$. polycarpos.

Acknowledgement: The authors wish to thank Mr. Ehsan Khedive for his help with the statistical procedures and the guidelines on the calculations of the germination parameters.

\section{$\underline{\text { References }}$}

Adams, R.P. (2014) "Junipers of the World: The Genus Juniperus". Trafford Publishing.

Ahani, H., Jalilvand, H., Nasr, S.M.H., Kouhbanani, H.S., Ghazi, M.R. and Mohammadzadeh, H. (2013) Reproduction of juniper (Juniperus polycarpos) in Khorasan Razavi, Iran. Forest Science and Practice, 15(3), 231-237.

Andersen, G.L., Krzywinski, K., Gjessing, H.K. and Pierce, R.H. (2016) Seed viability and germination success of Acacia tortilis along land-use and aridity gradients in the Eastern Sahara. Ecology and Evolution, 6(1), 256-266.

Barbour, J.R. and Carvalho, J.P. (2009) Response of Rocky Mountain juniper (Juniperus scopulorum) seeds to seed conditioning and germination treatments. Seed Technology, 43-54.

Baskin, C.C. (2017) Seed ecology: A diverse and vibrant field of study. Seed Science Research, 27(2), 61-64.

Baskin, C.C. and Baskin, J.M. (2014) "Seeds: Ecology, Biogeography, and Evolution of Dormancy and Germination", San Diego, USA: Academic Press.

Batygina, T.B. (2009) "Embryology of Flowering Plants: Terminology and Concepts. Volume 3: Reproductive Systems", Science Publishers, Inc.

Czabator, F.J. (1962) Germination value: An index combining speed and completeness of pine seed germination. Forest Science, 8(4), 386-396.

Daneshvar, A. (2015) "Improved Seed Handling Techniques for Juniperus polycarpos", Swedish University of Agricultural Sciences, Southern Swedish Forest Research Centre.

Daneshvar, A., Tigabu, M., Karimidoost, A. and Oden, P.C. (2015) Single seed Near Infrared Spectroscopy discriminates viable and non-viable seeds of Juniperus polycarpos. Silva Fennica, 49(5), 1-14.

Daneshvar, A., Tigabu, M., Karimidoost, A. and Odén, P.C. (2016) Stimulation of germination in dormant seeds of Juniperus polycarpos by stratification and hormone treatments. New Forests, 1-11. 
Daneshvar A., Tigabu, M., Karimidoost, A. and Odén, P.C. (2017) Flotation techniques to improve viability of Juniperus polycarpos seed lots. Journal of Forestry Research, 28(2), 231-239.

Darrudi, R., Hassandokht, M.R. and Nazeri, V. (2015) Effects of moist stratification, GA3 and seed age on seed germination of Rheum khorasanicum B. Baradaran \& A. Jafari. Journal of Applied Research on Medicinal and Aromatic Plants, 2(4), 168-173.

El-Juhany, L.I., Aref, I.M. and Al-Ghamdi, M.A. (2009) Effects of different pre-treatments on seed germination and early establishment of the seedlings of Juniperus procera trees. World Application Science Journal, 7, 616-624.

Gomez, K.A. and Gomez, A.A. (1984) "Statistical Procedures for Agricultural Research", John Wiley \& Sons.

Gowthami, R., Raghavendra, K., Dhananivetha, M. and Shashank, R. (2016) Indigenous seed treatment methods to enhance germination and for control of pests and diseases. Asian Agri-History, 20(2).

Guerrant Jr, E.O., Havens, K., Vitt, P., Fiedler, P.L., Falk, D.A. and Dixon, K. (2015) Population structure integral to seed collection guidelines: A response to Hoban and Schlarbaum (2014). Biological Conservation, 184, 465-466.

Kerdaffrec, E. and Nordborg, M. (2017) The maternal environment interacts with genetic variation in regulating seed dormancy in Swedish Arabidopsis thaliana. PloS One, 12(12), e0190242.

Kharazipour, A.R. (2009) Review of forests, wood products and wood biotechnology of Iran and Germany: Universitätsverlag Göttingen.

Koornneef, M., Bentsink, L. and Hilhorst, H. (2002) Seed dormancy and germination. Current Opinion in Plant Biology, 5(1), 33-36.

Korouri, A.A.S., Khoshnevis, M. and Matinizadeh, M. (2012) Comprehensive studies of Juniperus species in Iran. Tehran, Iran. (In Persian): Forest, Range and Watershed Management Organization.

Mamo, N., Mihretu, M., Fekadu, M., Tigabu, M. and Teketay, D. (2006) Variation in seed and germination characteristics among Juniperus procera populations in Ethiopia. Forest Ecology and Management, 225(1-3), 320-327.

Martins, A.M. and Engel, V.L. (2007) Soil seed banks in tropical forest fragments with different disturbance histories in southeastern Brazil. Ecological Engineering, 31(3), 165-174.

Mitchell, J.E. and Roberts Jr, T.C. (1999) Distribution of pinyon-juniper in the western United States, Proceedings of the Ecology and Management of Pinyon-juniper Communities Within the Interior West. USDA Forest Service Proceedings RMRS-P-9. Rocky Mountain Research Station, Fort Collins, CO. pp. 146-154.

Peel, M.C., Finlayson, B.L. and McMahon, T.A. (2007) Updated world map of the Köppen-Geiger climate classification. Hydrology and Earth System Sciences, 11(5), 1633-1644.

Penfield, S, (2017) Seed dormancy and germination. Current Biology, 27(17), R874-R878.

Pinna, M.S., Mattana, E., Cañadas, E.M. and Bacchetta, G. (2014) Effects of pre-treatments and temperature on seed viability and germination of Juniperus macrocarpa Sm. Comptes Rendus Biologies, 337 (5), 338-344.

Ramsfield, T., Bentz, B., Faccoli, M., Jactel, H. and Brockerhoff, E. (2016) Forest health in a changing world: Effects of globalization and climate change on forest insect and pathogen impacts. Forestry, 89 (3), 245-252.

Rugemalila, D.M., Morrison, T., Anderson, T.M. and Holdo, R.M. (2017) Seed production, infestation, and viability in Acacia tortilis (synonym: Vachellia tortilis) and Acacia robusta (synonym: Vachellia robusta) across the Serengeti rainfall gradient. Plant Ecology, 218(8), 909-922.

Santos, T. and Tellería, J. (1994). Influence of forest fragmentation on seed consumption and dispersal of Spanish juniper Juniperus thurifera. Biological Conservation, 70(2), 129-134.

Tauer, P.K., Will, R.E. and Porterfield, J.D. (2011) Effects of seed source and pre-planting treatment on emergence of Juniperus scopulorum Sarg. in a Great Plains nursery. Native Plants Journal, 12(3), 241-248. 
Tilki, F. (2007) Preliminary results on the effects of various pre-treatments on seed germination of Juniperus oxycedrus L. Seed Science and Technology, 35(3), 765-770.

Tillman-Sutela, E. and Kauppi, A. (2014) Maturity of surface structures in northern Pinus sylvestris L. seeds: A key to improved prediction of germination potential. Flora - Morphology, Distribution, Functional Ecology of Plants, 209(1), 45-53.

Tylkowski, T. (2009) Improving seed germination and seedling emergence in the Juniperus communis. Dendrobiology, 61, 47-53.

Yuan, W., Flowers, J.M., Sahraie, D.J. and Purugganan, M.D. (2016) Cryptic genetic variation for Arabidopsis thaliana seed germination speed in a novel salt stress environment. G3: Genes, Genomes, Genetics, 6(10), 3129-3138.

(Received 19/ 12 /2017; accepted 21 / 5 /2018) 